\title{
Prevalence of tobacco use in selected Johannesburg suburbs
}

\author{
J A Teare ${ }^{1,4}$ MSc; N Naicker, ${ }^{1,2,3,4,5}$ MB BCh, FCPHM, MMed, PhD; P Albers, ${ }^{1}$ MSc; A Mathee,${ }^{1,2,3,4} \mathrm{PhD}$ \\ ${ }^{1}$ Environment and Health Research Unit, South African Medical Research Council, Johannesburg, South Africa \\ ${ }^{2}$ Department of Environmental Health, Faculty of Health Sciences, University of Johannesburg, South Africa \\ ${ }^{3}$ School of Public Health, Faculty of Health Sciences, University of the Witwatersrand, Johannesburg, South Africa \\ ${ }^{4}$ Department of Environmental Health, School of Behavioural Sciences, Faculty of Health Sciences, Nelson Mandela University, Port Elizabeth, \\ South Africa \\ ${ }^{5}$ Epidemiology and Surveillance Section, National Institute of Occupational Health, National Health Laboratory Services, Johannesburg, \\ South Africa
}

Corresponding author: J A Teare (june.teare@mrc.ac.za)

Background. Tobacco smoking is estimated to kill more than 44000 South Africans every year. Studies have shown that since the introduction of tobacco control measures, national smoking prevalence has declined in South Africa (SA).

Objective. To determine the prevalence of tobacco smoking over a 7-year period in five impoverished neighbourhoods in Johannesburg, SA. Methods. Data were collected through the annual administration of a prestructured questionnaire to one adult respondent in preselected dwellings from 2006 to 2012. Information was collected on socioeconomic status, smoking practices and health status.

Results. Over the 7-year period of the analysis, smoking levels remained unchanged. The proportion of households with one or more smokers varied significantly across the five study neighbourhoods. Approximately $20 \%$ of households in Hillbrow and as many as $77 \%$ in Riverlea had a member who smoked.

Conclusions. Despite a national downward trend in smoking levels, tobacco use remains high and persistent in certain vulnerable communities, requiring scaled-up action to reduce the risk of a range of tobacco-related diseases.

S Afr Med J 2018;108(1):40-44. DOI:10.7196/SAMJ.2018.v108i1.12283

Worldwide, an estimated five million deaths per year are caused by tobacco use, and this figure is expected to exceed eight million by the year 2030 ${ }^{[1]}$ Common health risks associated with smoking include heart disease, chronic obstructive pulmonary disease, lung cancer and stroke. ${ }^{[1]}$ International studies have shown that the lifespan of smokers is reduced by 10 years relative to non-smokers. ${ }^{[2]}$ In South Africa (SA), smoking has been found to account for $8-9 \%$ of the burden of mortality. ${ }^{[3]}$ Age, gender, ethnic group and economic status are among the factors associated with smoking prevalence, ${ }^{[4,5]}$ and there appears to be an inverse association between social status and smoking, in that $82 \%$ of the world's smokers live in low- and middleincome countries. ${ }^{[1]}$ In SA, the most frequent tobacco users have been identified as poor men and women with low levels of education and income, and living in urban areas. ${ }^{[4,6]}$

Second-hand smoke (SHS) and passive/secondary smoking are terms used for smoked tobacco present in the atmosphere and to which non-smokers are exposed. The use of tobacco by one or more adults impacts negatively on the health of children and other adults living in the same household. ${ }^{[7]}$ In 2004, global estimates showed that $40 \%$ of children, $35 \%$ of female non-smokers and $33 \%$ of male nonsmokers were exposed to SHS, and the number of deaths resulting from this exposure was estimated at $603000 ; 28 \%$ (166 000) of these deaths were of children aged $<5$ years. ${ }^{[8]}$ In children, SHS has been associated with lower respiratory tract illnesses, acute and chronic middle ear infections, chronic respiratory symptoms, asthma and reduced lung function, and there is evidence suggesting a link between SHS and childhood cancers. ${ }^{[9]}$

While studies have indicated an overall downward trend in levels of smoking in SA in recent years, ${ }^{[10,11]}$ there is limited information available on smoking patterns at a disaggregated household level.
This is especially pertinent to the rapidly changing urban context in SA, where cities such as Johannesburg have seen rapid growth associated with urbanisation in recent decades, with influx from both the rural hinterlands and elsewhere on the African continent. This article, which describes smoking levels in five relatively impoverished Johannesburg neighbourhoods, contributes to the need for information on smoking in a rapidly changing urban African context.

\section{Objective}

To determine the prevalence of tobacco use in selected settings of poverty in Johannesburg between 2006 and 2012.

\section{Methods}

Sampling and data collection

The Health, Environment and Development (HEAD) study is a Johannesburg-based panel study initiated in 2006, involving annual cross-sectional surveys (panel study) of urban environment and health trends, where data are collected from the same dwellings (unit of analysis) in each site every year. ${ }^{[12,13]}$ The HEAD study was undertaken in five Johannesburg neighbourhoods: Bertrams (a run-down inner-city suburb with a mixed residential-commercial character), Hillbrow (a densely populated, high-rise inner-city area), Riverlea (an apartheid-era township constructed in the early 1960s), Braamfischerville (a democratic-era, low-cost, mass-based housing development), and Hospital Hill (an informal settlement on the city's western boundary).

Dwellings were randomly selected in the neighbourhoods where planning maps were available (Bertrams, Riverlea and Braamfischerville). Systematic sampling was used in the high-rise 
study area of Hillbrow, while in Hospital Hill, where no planning maps were available on initiation of the study, convenience sampling was used. The main study outcomes included environmental risk factors and health outcomes. The prevalence for the various outcomes therefore varied. Based on resources available at the time, it was decided to sample 200 stands/plots/households in each of the five sites. After excluding commercial and empty plots, the final sample size shown in Table 1 was selected. For this article, the prevalence of tobacco smoking among SA adults was taken to be $\sim 18 \%{ }^{[11]}$ The desired margin of error was $5 \%$. The power of the study was calculated at $>90 \%$ for a sample size of 548 in 2012.

Data were collected in the selected dwellings using prestructured questionnaires administered to an adult member (respondent) of the main household on each dwelling site (secondary individuals or households living on the site were not considered). The questionnaire was tested in a pilot study in 2005 before commencement of the first study in 2006. Since the primary unit of selection was the dwelling, households and/or respondents could have changed over the 7-year period. Table 1 illustrates the response rates per year and per site over the 7-year period.

Interviews were undertaken by environmental health students from the University of Johannesburg's Faculty of Health Sciences. Ethical approval for the study was obtained from the University of Witwatersrand Human Research Ethics Committee (Medical) in 2005 prior to initiation of the study (ref. no. M050451), and renewed in March 2010 for a further 5 years (ref. no. M10471).

Among other variables, data were collected on socioeconomic status, migration patterns, neighbourhood environmental conditions, housing, health status and tobacco use practices. ${ }^{[12]}$ For the purpose of this article, data on smoking prevalence were analysed for the 7-year period from 2006 to 2012. For analyses of the association between household tobacco use and health, data from the year 2012 were used.

\section{Data analysis}

Dependent variables. Respondents were asked whether any member of the household smoked - if one or more members in a particular household smoked, it was defined as a smoking household. No information on the method of smoking was obtained. For the purposes of this study, tobacco use was therefore defined as the smoking of cigarettes (manufactured or hand rolled) or pipe (traditional or hookah/hubbly bubbly).

Independent variables included study site and household-level characteristics (socioeconomic status, demographic characteristics and health status). Data were entered into the EpiData statistical analysis package, version 3.1 (EpiData, Denmark). The data were exported into the Stata statistical package, version 14 (StataCorp, USA), for analysis. Data for each site were weighted and the Stata survey command was used for analysis to minimise the effect of clustering and adjust for the study design. The trend analysis was calculated using the np trend command. Frequencies of various independent variables were calculated for those households that had reported a member smoking and those that had not. Data from the 2012 survey were used to explore various factors potentially associated with smoking. This was done on the bivariate level using logistic regression with crude odds ratios. A $p$-value of $<0.05$ was considered statistically significant. Plausible factors that showed possible significance $(p<0.25)$ at the bivariate level were included in multivariate forward stepwise logistic regression models.

\section{Results}

\section{Study population}

The profile (2012) of the population in the five study sites is given in Table 2. It can be seen that the study samples differed considerably across the five sites, including in terms of their main population groups (as defined during the apartheid era of government), proportion of households headed by migrants from other countries, tertiary educational attainment, employment status, income and household composition (households with and without children aged $<5$ years). Overall, households in Hillbrow, which had the highest proportion of households headed by a migrant from another country, tended to have higher levels of education, employment and income, while households in the informal settlement of Hospital Hill and in Riverlea were of relatively low socioeconomic status. Hillbrow also had the lowest proportion of households with one or more children aged $<5$ years and the lowest level of expenditure on tobacco.

\section{Tobacco use prevalence}

In the total study sample, the proportion of households with one or more smokers ranged from $41.8 \%$ to $52.7 \%$ over the 7 -year period of the study (Fig. 1). The trend analysis showed the overall increase to be insignificant $(p=0.4)$.

A breakdown of levels of tobacco use by study site indicated considerable variation, with Riverlea consistently having the highest prevalence. Riverlea also had the highest level of expenditure on tobacco and the highest proportion of households that included a child aged $<5$ years. In contrast, the lowest prevalence of tobacco use was in Hillbrow (Fig. 2), so Hillbrow was chosen as the area of reference for the bivariate analysis (Table 3 ).

Table 1. Response rates (primary households in each dwelling) per year and per site over the study period

\begin{tabular}{|c|c|c|c|c|c|c|}
\hline Year & $\begin{array}{l}\text { Hospital Hill } \\
(N=188), \\
n(\%)\end{array}$ & $\begin{array}{l}\text { Riverlea }(N=158), \\
n(\%)\end{array}$ & $\begin{array}{l}\text { Braamfischerville } \\
(N=188), \\
n(\%)\end{array}$ & $\begin{array}{l}\text { Bertrams }(N=132) \text {, } \\
n(\%)\end{array}$ & $\begin{array}{l}\text { Hillbrow }(N=142), \\
n(\%)\end{array}$ & $\begin{array}{l}\text { Total }(N=808), \\
n(\%)\end{array}$ \\
\hline 2006 & $104(55.3)$ & $101(63.9)$ & $122(64.9)$ & $69(52.3)$ & $128(90.1)$ & $524(64.9)$ \\
\hline 2007 & $101(53.7)$ & $102(64.5)$ & $151(80.3)$ & $53(40.1)$ & $69(48.6)$ & $476(58.9)$ \\
\hline 2008 & $100(53.2)$ & $91(57.7)$ & $101(53.7)$ & $59(44.7)$ & $68(47.9)$ & $419(51.9)$ \\
\hline 2009 & $74(39.4)$ & $92(58.2)$ & $117(62.2)$ & $51(38.6)$ & $52(36.6)$ & $386(47.7)$ \\
\hline 2010 & $172(91.5)^{*}$ & $120(75.9)$ & $143(76.1)$ & $51(38.6)$ & $62(43.7)$ & $548(67.8)$ \\
\hline 2011 & $108(57.4)$ & $106(67.0)$ & $124(65.9)$ & $53(40.2)$ & $52(36.6)$ & $443(54.8)$ \\
\hline 2012 & $138(73.4)$ & $124(78.4)$ & $147(78.2)$ & $73(55.3)$ & $66(46.5)$ & $548(67.8)$ \\
\hline $\begin{array}{l}\text { Average over } \\
7 \text { years }\end{array}$ & $114(60.6)$ & $105(66.4)$ & $130(69.1)$ & $58(43.9)$ & $71(50.0)$ & $478(59.2)$ \\
\hline
\end{tabular}


Table 2. Profile of the study populations for 2012

\begin{tabular}{|c|c|c|c|c|c|}
\hline Variable & $\begin{array}{l}\text { Hospital Hill } \\
(N=138) \\
n(\%)\end{array}$ & $\begin{array}{l}\text { Riverlea } \\
(N=124), \\
n(\%)\end{array}$ & $\begin{array}{l}\text { Braamfischerville } \\
(N=147) \\
n(\%)\end{array}$ & $\begin{array}{l}\text { Bertrams } \\
(N=73), \\
n(\%)\end{array}$ & $\begin{array}{l}\text { Hillbrow } \\
(N=66), \\
n(\%)\end{array}$ \\
\hline \multicolumn{6}{|l|}{ Place of birth } \\
\hline South Africa & $119(86.2)$ & $124(100.0)$ & 145 (98.6) & $60(82.2)$ & $34(51.6)$ \\
\hline Elsewhere & $19(13.8)$ & 0 & $2(1.4)$ & $13(18.0)$ & $32(48.5)$ \\
\hline \multicolumn{6}{|l|}{ Population group } \\
\hline Black African & $138(100.0)$ & $12(9.7)$ & $146(99.3)$ & $47(64.4)$ & $65(98.5)$ \\
\hline Coloured & 0 & $112(90.3)$ & $1(0.7)$ & $10(13.7)$ & 0 \\
\hline Other (white, Indian) & 0 & 0 & 0 & $16(21.9)$ & $1(1.5)$ \\
\hline Households with children $<5$ years of age & $64(46.4)$ & $64(51.6)$ & $63(42.9)$ & $28(38.4)$ & $19(28.8)$ \\
\hline Head of household has tertiary education & $3(2.2)$ & $5(4.0)$ & $18(12.2)$ & $3(4.1)$ & $18(27.3)$ \\
\hline $\begin{array}{l}\text { Head of household has full-time } \\
\text { employment }\end{array}$ & $10(7.2)$ & $13(10.5)$ & $27(18.4)$ & $18(24.7)$ & $32(48.5)$ \\
\hline \multicolumn{6}{|l|}{ Household income (ZAR) } \\
\hline$\leq 1000$ & $57(41.3)$ & $36(29.0)$ & $33(22.4)$ & $8(10.9)$ & $4(6.1)$ \\
\hline $1001-5000$ & $58(42.0)$ & $52(41.9)$ & $71(48.3)$ & $40(54.8)$ & $28(42.4)$ \\
\hline$>5000$ & $19(13.8)$ & $31(25.0)$ & $39(26.5)$ & $24(32.9)$ & $34(51.5)$ \\
\hline Government grant $^{*}$ (at least one grant) & $67(48.6)$ & $80(64.5)$ & $72(48.9)$ & $31(42.5)$ & $7(10.6)$ \\
\hline $\begin{array}{l}\text { Mean monthly expenditure on tobacco } \\
\text { (ZAR) }\end{array}$ & 38.80 & 140.80 & 24.08 & 92.95 & 15.15 \\
\hline
\end{tabular}

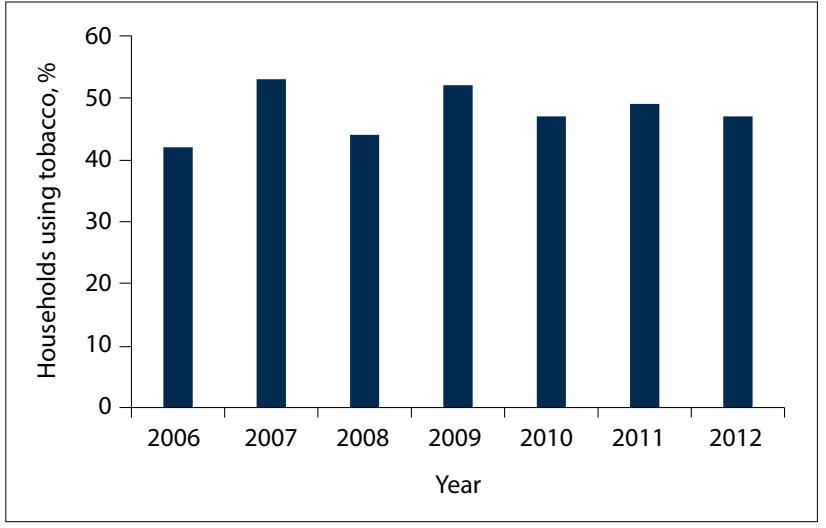

Fig. 1. Tobacco use in households by year, 2006 - 2012 (total sample).

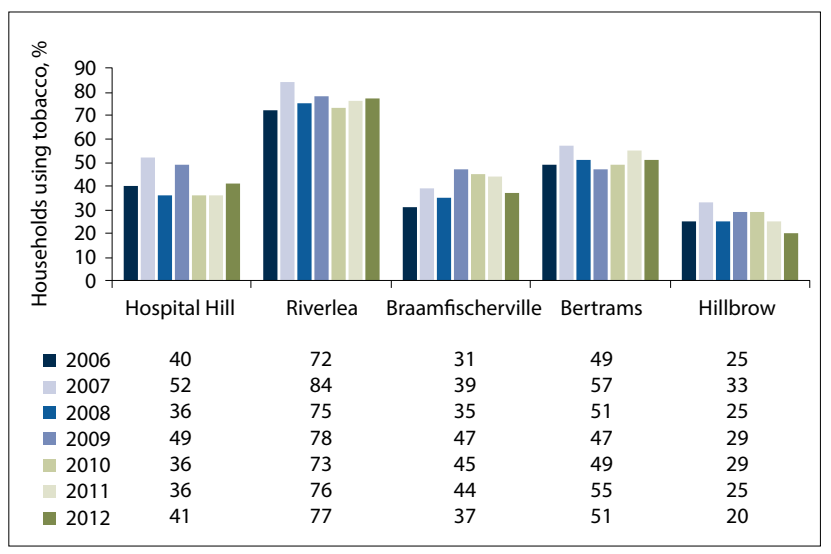

Fig. 2. Prevalence of tobacco use per year and per site.

\section{Risk factors for elevated tobacco use (2012)}

The socioeconomic and demographic profile for households reporting tobacco use $(n=257,46.7 \%)$ for 2012 is shown in Table 3. Compared with Hillbrow, smoking prevalence for the remaining four neighbourhoods was significantly elevated: Hillbrow $19.7 \%$ v. Hospital Hill 40.6\% ( $p=0.004)$, Riverlea 77.4\% ( $p=0.000)$, Braamfischerville $37.4 \%(p=0.013)$ and Bertrams 50.7\% $(p=0.000)$. Smoking levels were also significantly elevated in households headed by an individual born in SA relative to elsewhere $(48.9 \%$ v. $31.9 \% ; p=0.01 ; 95 \%$ confidence interval (CI) 0.28 - 0.842). In this study, levels of smoking were not associated with the educational status or income of the head of the household. Smoking levels were, however, elevated in households with heads who were not in full-time employment ( $p=0.05$; 95\% CI 0.998 2.414) or who had been born in SA rather than being a migrant from another country ( $p=0.01 ; 95 \%$ CI $0.28-0.842$ ), and in households that had a member who received a government grant $(p=0.005 ; 95 \%$ CI 1.163 - 2.256). However, after controlling for socioeconomic status and study area, none of the risk factors remained significantly associated with household smoking status.

Bivariate analyses indicated statistically significant associations between households with a member who smoked and a member who reported acute respiratory symptoms (2-week recall period), asthma, hypertension, heart disease or stroke (1-year recall period). However, after adjusting for socioeconomic factors and study site, smoking prevalence was not associated with household-level ill health.

\section{Discussion}

Over the 7-year study period, no statistically significant change in levels of smoking occurred in the total sample. This finding contrasts with the finding at national level of an overall downward trend in smoking prevalence since the introduction of the Tobacco Products Control Act of 1993. ${ }^{[14]}$ National tobacco smoking levels for 2010 were 19.4\% (upper CI 24.1), declining to $18.2 \%$ (upper CI 23.8) by 2015. ${ }^{[15]}$ In contrast, this study shows that in certain neighbourhoods, such as Riverlea, tobacco consumption continues to be highly elevated.

The relatively low levels of tobacco use in Hillbrow (19.7\% of households had a member who smoked) may be attributable to the high proportion of respondents who were migrants from other countries. In the current study, the vast majority of international migrant household heads had originated from elsewhere in Africa. 
Table 3. Bivariate analysis of the socioeconomic and demographic profile of households reporting tobacco use for 2012

\begin{tabular}{|c|c|c|c|c|}
\hline Variable & $\begin{array}{l}\text { Prevalence of } \\
\text { reported smoking } \\
(N=257,46.7 \%), \\
n(\%)\end{array}$ & Crude OR & $p$-value & $95 \%$ CI \\
\hline \multicolumn{5}{|l|}{ Study site } \\
\hline Hospital Hill $(n=138)$ & $56(40.6)$ & 2.78 & 0.004 & $1.381-5.612$ \\
\hline Riverlea $(n=124)$ & $96(77.4)$ & 13.97 & 0.000 & $6.637-29.439$ \\
\hline Braamfischerville $(n=147)$ & $55(37.4)$ & 2.44 & 0.013 & $1.212-4.902$ \\
\hline Bertrams $(n=73)$ & $37(50.7)$ & 4.19 & 0.000 & $1.944-9.031$ \\
\hline Hillbrow (ref) $(n=66)$ & $13(19.7)$ & ref & - & - \\
\hline \multicolumn{5}{|c|}{ Migration status (place of birth of head of household) } \\
\hline South African $(n=482)$ & 236/ 482 (48.9) & & & \\
\hline Non-South African $(n=66)$ & $21 / 66(31.9)$ & 0.48 & 0.01 & $0.28-0.842$ \\
\hline \multicolumn{5}{|c|}{ Households with children $<5$ years of age ${ }^{*}$} \\
\hline None $(n=295)$ & $139(47.1)$ & & & \\
\hline One or more $(n=238)$ & $109(45.8)$ & 0.95 & 0.76 & $0.674-1.335$ \\
\hline \multicolumn{5}{|c|}{ Head of household has tertiary education* } \\
\hline No $(n=479)$ & $223(46.6)$ & & & \\
\hline Yes $(n=47)$ & $21(44.7)$ & 0.97 & 0.81 & $0.513-1.677$ \\
\hline \multicolumn{5}{|c|}{ Head of household has full-time employment ${ }^{*}$} \\
\hline No $(n=441)$ & $215(48.8)$ & & & \\
\hline Yes $(n=100)$ & $38(38.0)$ & 1.55 & 0.05 & $0.998-2.414$ \\
\hline \multicolumn{5}{|l|}{ Household income (ZAR)* } \\
\hline$<1000(n=138)$ & $68(49.3)$ & ref & & \\
\hline $1001-5000(n=249)$ & $125(50.2)$ & 1.04 & 0.86 & $0.685-1.573$ \\
\hline$>5000(\mathrm{ref})(n=147)$ & $60(40.8)$ & 0.71 & 0.15 & $0.445-1.131$ \\
\hline \multicolumn{5}{|l|}{ Government grant $^{\dagger}$} \\
\hline None $(n=291)$ & $120(41.2)$ & & & \\
\hline At least one grant $(n=257)$ & $137(53.3)$ & 1.63 & 0.005 & $1.163-2.256$ \\
\hline
\end{tabular}

Global estimates of tobacco use show that SA has a relatively low prevalence of smoking ${ }^{[15]}$ compared with the USA, ${ }^{[16]}$ Europe and Asia, ${ }^{[15]}$ but a higher prevalence than neighbouring African countries such as Zimbabwe and Malawi. ${ }^{[15]}$

Concomitant with the significantly elevated levels of smoking in Riverlea, these households also spent more than nine times as much money on tobacco as Hillbrow households, despite the lower socioeconomic status in Riverlea. There is concern regarding childhood exposure to SHS in Riverlea, which also had the highest proportion of households with children aged $<5$ years. The findings of this study are in keeping with previous SA studies that have found particularly elevated levels of tobacco use and tobacco-related deaths in coloured communities, while black African communities had the lowest levels. ${ }^{[4,6]}$ Smokers in the coloured population have been reported to have a $50 \%$ higher overall mortality than otherwise similar non-smokers or ex-smokers. ${ }^{[17]}$ With regard to exposure to SHS, an SA birth cohort study showed that coloured children were most frequently exposed to SHS owing to the presence of a primary caregiver who smoked; $42 \%$ of children lived in homes with two or more smokers. ${ }^{[18]}$ The present study confirms the need for scaledup action to reduce smoking levels and the associated ill-health outcomes in vulnerable neighbourhoods such as Riverlea.

Stringent tobacco control policies in developed countries have resulted in low levels of tobacco consumption. This declining demand for tobacco products and a difficult tobacco market have triggered aggressive tobacco sales strategies in low- and middle-income
African countries. ${ }^{[19]}$ Young people in particular are being targeted by tobacco companies by the placement of products in movies and music videos and distribution of tobacco products at student parties, and by appealing to the naturally rebellious nature of adolescents. ${ }^{[10]}$ SA studies relating to the initiation of smoking have shown that with each successive generation individuals began smoking at a younger age, proving that the tobacco industry is having success in recruiting adolescent smokers. ${ }^{[10]}$ Prevention and cessation efforts should therefore focus on the youth. In addition, the rising income in fast-growing countries increases the affordability of cigarettes in the majority of low- and middle-income countries. ${ }^{[20]}$ However, of the tobacco control policies in place in SA, tobacco price increases have been shown to be the most effective intervention. Other factors associated with an increase in tobacco use in low socioeconomic areas are low levels of education and low status of workers. ${ }^{[21]}$

\section{Study limitations}

A limitation to this study may be information bias at respondent level, outcomes for this interview-based study having been constructed on the respondent's ability to recollect household events and activities accurately. ${ }^{[22]}$ For example, difficulty may be experienced by a respondent who is requested for household information in an impromptu scenario, or who may be ignorant of certain information such as household earnings. Findings may also have been affected by incomplete data and lower response rates in some study sites (Bertrams and Hillbrow), which were affected by xenophobic violence 
during 2008/2009. ${ }^{[23]}$ Limitations of the cross-sectional study design are applicable to this study as well, in that the study reflected information at one point in time only and the incidence of smoking could not be measured in the sample over the 7 -year period. ${ }^{[24]}$ In addition, associations that were determined in the multivariate analyses may be difficult to interpret owing to the study design; no data were available on individual household members who engaged in smoking and the health effects on them, so we were not able to comment on any individual risk factors for/consequences of smoking.

\section{Conclusions}

Our study confirms that in spite of the national downward trend in smoking prevalence, levels of tobacco use continue to be highly elevated in certain groups and settings. Scaled-up action is required in such vulnerable communities to reduce tobacco use and the associated ill-health conditions. Efforts towards smoking prevention and cessation should include specifically designed interventions according to age, culture and living conditions.

Acknowledgements. We thank the community members who participated in the project by generously offering their time and responses. We also thank the environmental health students of the University of Johannesburg who diligently collected the data.

Author contributions. AM and NN conceptualised and designed the study, PA and NN analysed the data, and JAT led the writing with participation and constructive discussion from AM, NN and PA.

Funding. This study was made possible by funding from the South African Medical Research Council.

Conflicts of interest. None.

1. World Health Organization. Systematic Review of the Link between Tobacco and Poverty. Geneva WHO, 2011. http://libdoc.who.int/publications/2011/9789241500548_eng.pdf (accessed 4 March 2016).

2. Doll R, Peto R, Boreham J, Sutherland I. Mortality in relation to smoking: 50 years' observations on male British doctors. BMJ 2004;328:1519. https://doi.org/10.1136/bmj.38142.554479.ae

3. Groenewald P, Vos T, Norman R, et al. Estimating the burden of disease attributable to smoking in South Africa in 2000. S Afr Med J 2007;97(8):674-681.

4. Steyn K, Bradshaw D, Norman R, Laubscher R, Saloojee Y. Tobacco use in South Africans during 1998: The first demographic and health survey. Eur J Prev Cardiol 2002;9(3):161-170. https://doi.org/10.117
7\%2F174182670200900305 Erratum in Eur J Prev Cardiol 2002;9(4):inside back cover. http://journals. sagepub.com/doi/pdf/10.1177/174182670200900407 (accessed 14 December 2016).
5. Lim KH, Jasvindar K, Cheong SM, et al. Prevalence of smoking and its associated factors with smoking among elderly smokers in Malaysia: Findings from a nationwide population-based study. Tob Induc Dis 2016;14:8. https://doi.org/10.1186/s12971-016-0073-z

6. Van Walbeek C. Economics of Tobacco Control Project - Phase II. The tobacco epidemic can be 6. Wan be Economics, University of Cape Town, 2002. http://s3.amazonaws.com/zanran_storage/www.idrc.org. Economics, University of Cape Town, 2002. http://s3.amazonaws
sg/ContentPages/1302304619.pdf (accessed 13 October 2016).

$\mathrm{sg} /$ ContentPages/1302304619.pdf (accessed 13 October 2016).
7. World Health Organization. The World Health Organization Report on the Global Tobacco Epidemic World Health Organization. The World Health Organization Report on the Global Tobacco Epidemic,
2008: The MPOWER Package. Geneva: WHO, 2008. http://www.who.int/tobacco/mpower/mpower_ report_full_2008.pdf (accessed 29 March 2016).

8. Öberg M, Jaakkola MS, Woodward A, Peruga A, Prüss-Ustün A. Worldwide burden of disease from exposure to second-hand smoke: A retrospective analysis of data from 192 countries. Lancet 2011;377(9760):139-146. https://doi.org/10.1016/s0140-6736(10)61388-8

9. World Health Organization. Tobacco Free Initiative: International Consultation on Environmental Tobacco Smoke (ETS) and Child Health. Geneva: WHO, 1999. http://www.who.int/entity/tobacco/ research/en/ets_report.pdf (accessed 4 March 2016).

10. Shisana O, Labadarios D, Rehle T, et al. The South African National Health and Nutrition Examination Survey (SANHANES-1). Cape Town: HSRC Press, 2013. http://www.hsrc.ac.za/uploads/pageNews/72/ SANHANES-launch\%20edition\%20(online\%20version).pdf (accessed 7 April 2016).

11. Reddy P, Zuma K, Shisana O, Jonas K, Sewpaul R. Prevalence of tobacco use among adults in South Redy P, Zuma K, Shisana O, Jonas K, Sewpaul R. Prevalence of tobacco use among adults in South Africa: Results from the first South African national health and nut

12. Mathee A. Indicators of Health Environment and Development: Longitudinal study in Johannesburg 2006 - 2008 Johannesburg: Environmental and Health Research Unit, South African Medical Research Council, 2009. http://www.mrc.ac.za/environmenthealth/head0608.pdf (accessed 13 December 2016).

13. Mathee A, Harpham T, Naicker N, et al. Overcoming fieldwork challenges in urban health research in developing countries: A research note. Int J Soc Res Method 2010;13(2):171-178. https://doi. org/10.1080/13645570902867742

4. Ayo-Yusuf OA, Olutola BG. 'Roll-your-own' cigarette smoking in South Africa between 2007 and 2010 . BMC Public Health 2013;13(1):597. https://doi.org/10.1186/1471-2458-13-597

15. World Health Organization. WHO Global Report on Trends in Prevalence of Tobacco Smoking 2015. Geneva: WHO, 2015. http://apps.who.int/iris/bitstream/10665/156262/1/9789241564922_eng. pdf?ua $=1$ (accessed 23 June 2016).

16. Centers for Disease Control and Prevention. Current Cigarette Smoking Among Adults - United States, 2005 - 2014. MMWR 2015;64(44):1233-1240. https://doi.org/10.15585\%2Fmmwr.mm6444a2

17. Sitas F, Egger S, Bradshaw D, et al. Differences among the coloured, white, black, and other South African populations in smoking-attributed mortality at ages $35-74$ years: A case control study of African populations in smoking-attributed mortality at ages 35 - 74 years: A case control study of

18. Steyn K, de Wet T, Richter L, Cameron N, Levitt NS, Morrell C. Cardiovascular disease risk factors in 5-year-old urban South African children - the Birth to Ten study. S Afr Med J 2000;90(7):719-726.

19. Van Walbeek C. Why South Africa needs to up the ante against smoking again. The Conversation, Health \& Medicine, May 2016. http://theconversation.com/why-south-africa-needs-to-up-the-anteagainst-smoking-again-59922 (accessed 25 July 2017)

20. Blecher EH, van Walbeek CP. Cigarette affordability trends: An update and some methodological comments. Tob Control 2009;18(3):167-175. https://doi.org/10.1136\%2Ftc.2008.026682

21. Pampel F. Tobacco use in sub-Sahara Africa: Estimates from the demographic health surveys. Soc Sci Med 2008;66(8):1772-1783. https://doi.org/10.1016\%2Fj.socscimed.2007.12.003

22. Vandenbroucke JP, von Elm E, Altman DG, et al. Strengthening the reporting of observational studies in epidemiology (STROBE): Explanation and elaboration. PLoS Med 2007;4(10)e297:1628-1654. https://doi.org/10.1371\%2Fjournal.pmed.0040297

23. Kapp C. South Africa failing people displaced by xenophobia riots. Lancet 2008;371(9629):1986-1987. https://doi.org/10.1016/s0140-6736(08)60852-1

24. Morromi C, Myer L. Study design. In: Ehrlich R, Joubert G, eds. Epidemiology: A Research Manual for South Africa. 3rd ed. Cape Town: Oxford University Press Southern Africa, 2014:78-83. 